\title{
ARTÍCULO 25
}

\section{“Disposición Transitoria}

1. La aplicación del presente Convenio otorgará derecho a prestaciones por contingencias acaecidas con anterioridad a la fecha de su vigencia. No obstante, el pago de las mismas tendrá únicamente los efectos retroactivos previstos en la legislación del Estado Parte que las reconozca y no se realizará por períodos anteriores a la entrada en vigor del Convenio.

Las prestaciones que hayan sido denegadas o reconocidas por uno o varios Estados Parte antes de la entrada en vigor del presente Convenio, podrán ser revisadas al amparo del mismo, a petición del interesado. El derecho se adquirirá desde la fecha de la solicitud, salvo disposición más favorable del Estado Parte que lo revise. No se revisarán las prestaciones abonadas que hayan consistido en una cantidad única.

2. Todo período de seguro, cotización o empleo, acreditado bajo la legislación de un Estado Parte antes de la fecha de aplicación del presente Convenio en el Estado Parte interesado, se tomará en cuenta para la determinación de los derechos originados conforme al presente Convenio".

\section{DAVID CARVALHO MARTINS}

Profesor Invitado

Facultad de Derecho de la Universidad de Lisboa (Portugal) 


\title{
SUMÁRIO
}

As regras relativas à aplicação da Convenção no tempo estão consagradas no artigo 25. . No essencial, a Convenção não se aplica apenas a prestações por eventualidades futuras, mas também a prestações por eventualidades ocorridas antes da sua entrada em vigor. Todavia, a retroatividade tem efeitos restritos. Por outro lado, a determinação dos direitos decorrentes da Convenção deve ter em conta todos os períodos de seguro, de contribuição ou de emprego cumprido antes da sua entrada em vigor. Este artigo referese, ainda, à possibilidade de uma revisão de decisões anteriores.

PALAVRAS-CHAVE: Aplicação da lei no tempo, entrada em vigor, retroatividade, eficacia ex nunc, segurança social.

\section{RESUMEN}

Las reglas sobre la aplicación del Convenio en el tiempo están enunciadas en su artículo 25. En lo esencial, el Convenio no se aplica solo a prestaciones por contingencias futuras, sino también a prestaciones por contingencias acaecidas anteriores a su entrada en vigor. Sin embargo, la retroactividad tiene efectos limitados. Por otro lado, la determinación de los derechos originados por el Convenio debe tener en cuenta todo período de seguro, cotización o empleo anterior a su entrada en vigor. Este artículo también se refiere a la posibilidad de revisión de decisiones anteriores.

PALABRAS CLAVE: Aplicación de la ley en el tiempo, entrada en vigor, retroactividad, eficacia ex nunc, Seguridad Social.

\begin{abstract}
The rules on the application of the Convention "ratione temporis" are set out in Article 25. In a few lines, the Convention applies not only to benefits for future contingencies, but also to benefits for contingencies that occurred prior to its entry into force. Still, retroactivity has limited effects. On the other hand, the determination of rights originated by the Convention must consider any period of insurance, contribution or employment prior to its entry into force. This article also refers to the possibility of reviewing previous decisions.
\end{abstract}

KEYWORDS: Application of the Convention "ratione temporis", entry into force, retroactivity, effectiveness, Social Security. 
SUMARIO

I. ÁMBITO DE APLICACIÓN TEMPORAL

II. CONVENCIÓN DE VIENA SOBRE EL DERECHO DE LOS TRATADOS

III. SEGURIDAD SOCIAL Y DERECHOS EN VÍAS DE ADQUISICIÓN

IV. LA INFLUENCIA DEL REGLAMENTO 883/2004

V. CONCLUSIONES 


\section{I. ÁMBITO DE APLICACIÓN TEMPORAL}

El ámbito de aplicación de un tratado internacional se basa en cuatro elementos: (i) subjetivo (las partes contratantes); (ii) material (el contenido); (iii) territorial (el espacio geográfico); y (iv) temporal ${ }^{1}$. El artículo 25 es una regla de derecho inter-temporal que busca solucionar el potencial conflicto de reglas resultante de la sucesión en el tiempo de regímenes legales. De hecho, regula la aplicación transitoria del Convenio.

\section{CONVENCIÓN DE VIENA SOBRE EL DERECHO DE LOS TRATADOS}

La Convención de Viena sobre el Derecho de los Tratados (Convención de Viena) ${ }^{2}$ - la cual no tiene eficacia retroactiva (artículo 4) en homenaje al principio de seguridad jurídica ${ }^{3}$-establece la irretroactividad de los tratados (artículo 28): éstos no deben producir efectos jurídicos o ser aplicables a las partes antes de su entrada en vigor ${ }^{4}$.

Por lo tanto, en general, los tratados o convenios tienen eficacia ex nunc: son aplicables a las situaciones, los hechos y los actos jurídicos que se produzcan después de su entrada en vigor; pero no a aquéllos que han ocurrido antes de ese momento ${ }^{5}$. En la práctica, las situaciones, hechos o actos jurídicos deben decidirse de acuerdo con las reglas en vigor en el momento de su verificación; la irretroactividad es, así, un principio general de Derecho Internacional y un supuesto esencial de la legalidad ${ }^{6}$. Debe señalarse que, sin embargo, no es cuestión pacífica si la irretroactividad es una costumbre internacional o un principio general de Derecho ${ }^{7}$.

El principio de irretroactividad significa que el nuevo tratado no es aplicable a los hechos acaecidos en el pasado, pero regula los hechos en desarrollo o pendientes en el momento de su entrada en vigor, así como a los futuros ${ }^{8}$.

De conformidad con el artículo 28 de la Convención de Viena, los Estados contratantes pueden determinar la eficacia retroactiva del tratado en su globalidad o de algunas de sus disposiciones. La retroactividad puede ser (i) expresamente incluida en el tratado, (ii) resultar de la interpretación del tratado (artículo 31.1 de la Convención de Viena) o

${ }^{1}$ Cfr. Odendahl K.; en: Dörr y Odenhal; Vienna Convention on the Law of Treaties: A Commentary. Springer, Berlin Heidelberg, 2012, p.477. De Oliveira Mazzuoli V.; The Law of Treaties: a Comprehensive Study of the 1969 Vienna Convention and Beyond. Editora Forense, Rio de Janeiro, 2016, p. 199.

${ }^{2} \mathrm{Cfr}$. http://www.wipo.int/export/sites/www/wipolex/es/glossary/vienna-convention-es.pdf (último acceso en 30.11.2016).

${ }^{3}$ Cfr. Odendahl K.; en: Dörr y Odenhal; Vienna Convention on the Law of Treaties. Op. cit., p. 478.

${ }^{4}$ Ibidem, p. 482.

${ }^{5}$ Ibidem, p. 483.

${ }^{6}$ Ibidem, p. 86.

${ }^{7}$ Ibidem, pp. 478-479.

${ }^{8}$ Ibidem, p. 485.

e-Revista Internacional de la Protección Social, ISNN 2445-3269. 2017, Vol. II, $\mathrm{N}^{\mathrm{o}} 1$ http://dx.doi.org/10.12795/e-RIPS.2017.i01.03

Página 20 
(iii) derivar de la naturaleza del tratado ${ }^{9}$. El Convenio Multilateral Iberoamericano de Seguridad Social ha optado por la vía expresa.

\section{SEGURIDAD SOCIAL Y DERECHOS EN VÍAS DE ADQUISICIÓN}

En materia de Seguridad Social, los derechos a prestaciones se basan en la conjunción de hechos y actos jurídicos que se devengan a lo largo de períodos temporales frecuentemente muy amplios (esto es típico de las prestaciones contributivas, a las cuales se les aplica el Convenio Multilateral Iberoamericano ${ }^{10}$ ); son derechos de formación sucesiva. El Convenio Multilateral es aplicable naturalmente a los hechos posteriores a su entrada en vigor, pero también a los derechos en formación. El artículo 25 busca soluciones para los derechos adquiridos o en curso de adquisición de los trabajadores migrantes y de sus familias, pero sin modificar los sistemas nacionales, a través del mecanismo de la coordinación o articulación multilateral (quinto considerando del Convenio Multilateral).

\section{LA INFLUENCIA DEL REGLAMENTO 883/2004}

Según SÁNCHEZ-RODAS, "resulta indudable que la redacción del articulado del Convenio Multilateral está inspirada en el Reglamento 883/2004". En efecto, hay numerosos artículos del primero que literalmente copian preceptos del segundo ${ }^{11}$. Así ocurre en este caso con relación al artículo 87del Reglamento 883/2004 ${ }^{12}$.

La redacción del número 1, primer y segundo párrafo de la Disposición Transitoria del Convenio Multilateral refleja la influencia del artículo 87.1 y 87.3 del Reglamento 883/2004. El artículo 87.1 del citado Reglamento establece que no origina ningún derecho para un período anterior a la fecha de su aplicación. Pero el artículo 87.3 previene que, a reserva del apartado 1, se originará un derecho en virtud del presente Reglamento, aunque se refiera a una eventualidad anterior a la fecha de su aplicación en el Estado miembro interesado. Es decir, se considera que un derecho es adquirido bajo el Reglamento aún que se refiera a una eventualidad ocurrida antes de la fecha de su aplicación en un Estado miembro.

\footnotetext{
${ }^{9}$ Ibidem, pp. 480-481.

${ }^{10}$ Articulo $3^{\circ}$, apartados 1, 2 y 4 del Convenio. Cfr. Sánchez-Rodas Navarro, C.; "Sinopsis del Reglamento 883/2004 y del Convenio Multilateral Iberoamericano de Seguridad Social" en VV.AA.; El Derecho del Trabajo en la Encrucijada: Retos para la Disciplina Laboral. Ediciones Laborum, Murcia, 2015, p. 187.

${ }^{11}$ Ibidem, p. 183.

${ }^{12}$ El Reglamento de Coordinación de los Sistemas de Seguridad Social fue modificado por los Reglamentos 988/2009, del Parlamento Europeo y del Consejo, de 16.9.2009; Reglamento 1244/2010 de la Comisión, de 9.12.2010; Reglamento 465/2012 del Parlamento Europeo y del Consejo, de 22.5.2012; Reglamento 1224/2012 de la Comisión, de 18.12.2012; Reglamento 517/2013 del Consejo, de 13.5.2013; Reglamento 1372/2013 de la Comisión, de 19.12.2013; y Reglamento 1368/2014 de la Comisión, de 17.12.2014.
}

e-Revista Internacional de la Protección Social, ISNN 2445-3269. 2017, Vol. II, N 1 http://dx.doi.org/10.12795/e-RIPS.2017.i01.03

Página 21 
Por su parte, el Convenio otorga derecho a prestaciones por contingencias acaecidas con anterioridad a la fecha de su vigencia, pero el pago de esas prestaciones tendrá únicamente los efectos retroactivos previstos en la legislación del Estado parte que las reconozca y no se realizará por períodos anteriores a la entrada en vigor del Convenio. La armonización es aquí muy limitada: los Estados parte quisieron reservar en la esfera de la soberanía nacional la definición del ámbito y alcance de la retroactividad. Lo que se puede comprender, teniendo en cuenta la imposibilidad de determinar a priori los importes que podrían ser debidos con soluciones multilaterales de retroactividad o bajo la decisión de otro Estado parte.

Los artículos 87.5 y 87.6 del Reglamento 883/2004 han influido también en el segundo párrafo del apartado $\mathrm{n}^{\circ} 1$ de la Disposición Transitoria del Convenio Multilateral Iberoamericano de Seguridad Social, porque se permite la revisión de las decisiones de denegación o de reconocimiento de prestaciones desde que el interesado presente su petición en ese sentido. Teniendo en cuenta que el procedimiento puede demorarse, sin que ello sea imputable al interesado, el Convenio establece que los efectos de esa revisión se producirán desde la fecha de la solicitud del interesado, salvo disposición más favorable del Estado Parte que lo revise. Así, la extensión de la revisión depende solamente de la diligencia del interesado a la hora de presentar su solicitud.

Esta regla está en línea con la eficacia ex nunc, porque no permite reconocer ipso iure, derechos y/o beneficios concedidos bajo el régimen anterior ${ }^{13}$, ni tampoco prestaciones denegadas.

Sin embargo, podrían ser ponderadas soluciones de retroactividad cuando las prestaciones hubieran sido denegadas o reconocidas por uno o varios Estados Parte antes de la entrada en vigor del Convenio Iberoamericano de Seguridad Social.

En todo caso, el principio del Estado de Derecho y su subprincipio fundamental de la tutela de la confianza legítima protegen a los interesados contra la supresión injustificada de derechos y/o beneficios garantizados bajo el régimen anterior, máxime cuando se trata de contingencias que requieren un período temporal de carencia y aportaciones del beneficiario a través de sus cotizaciones, las cuales pueden ser pagadas por sí o por su empleador. Esto no significa aún que exista un principio de no retroceso social, pero al revés que cualquier modificación de situaciones jurídicas existentes debe ser debidamente justificada y respetar la tríplice vertiente del principio de la proporcionalidad: adecuación, necesidad y prohibición del exceso.

También es factible que el tratado internacional determinase la atribución de los derechos o, prudentemente, la revisión casuística de las situaciones de los beneficiarios con arreglo a la nueva regulación. El número 1, segundo párrafo, de la Disposición Transitoria sigue este último camino. Esta regla presupone que el beneficiario evaluará, de forma prudente y diligente, la mayor favorabilidad de las reglas.

\footnotetext{
${ }^{13}$ Cfr. Odendahl K.; en: Dörr y Odenhal; Vienna Convention on the Law of Treaties. Op. cit., pp. 86-87.
}

e-Revista Internacional de la Protección Social, ISNN 2445-3269. 2017, Vol. II, N 1 http://dx.doi.org/10.12795/e-RIPS.2017.i01.03 
Por aplicación del principio de respeto por las situaciones jurídicas consolidadas, el apartado segundo in fine del número 1 de la Disposición Transitoria del Convenio Iberoamericano de Seguridad Social determina que la revisión no se aplica a las prestaciones abonadas que hayan consistido en una cantidad única.

El apartado 2 de la Disposición Transitoria del Convenio Multilateral Iberoamericano de Seguridad Social obliga a computar los períodos de seguro, cotización o empleo acreditados bajo la legislación de un Estado Parte antes de la fecha de aplicación del Convenio en el Estado Parte interesado para la determinación de los derechos previstos en el Convenio Iberoamericano.

$\mathrm{Y}$ es que si se considerasen solamente las situaciones, hechos y actos jurídicos posteriores a su entrada en vigor, la efectividad del Convenio se quedaría para las "calendas griegas", porque los derechos a prestaciones se basan en la conjugación de varios requisitos jurídicos que se producen durante largos períodos temporales.

\section{CONCLUSIONES}

Una nueva regulación que olvidase los hechos jurídicos (lato sensu) anteriores sería aplicable sólo para las generaciones futuras y, en una pequeña proporción, para los destinatarios actuales. Por eso hay que tener en cuenta que los efectos jurídicos previstos por el Convenio se pueden basar en hechos jurídicos duraderos o de formación sucesiva, total o parcialmente ocurridos en momento anterior a su fecha de entrada en vigor.

e-Revista Internacional de la Protección Social, ISNN 2445-3269. 2017, Vol. II, N 1 